\title{
The TopClosure ${ }^{\circledR}$ 3S System, for skin stretching and a secure wound closure by Topaz et al
}

\author{
Ian Jackson
}

Received: 7 December 2011 / Accepted: 7 December 2011 /Published online: 12 January 2012

(C) Springer-Verlag 2012

This is a very important paper because it devotes time to explain viscoelastic properties of the skin mainly creep and stress relaxation. These features of skin biomechanics are all important in order to deal with many of our plastic surgery skindefects. Using the understanding of safe skin stretching, large defects can be closed without developing ischemia and/ or necrosis. This is due to the skin entities of stress and skin relaxation. The authors have explained this very clearly and this will enable to neophyte to perform a tight and secure closure without concern.
I strongly advise that residents and perhaps others should read this paper. It will reduce the possibility of problems in difficult skin closures.

I thank Dr. Topaz et al. for submitting this important paper.

Ian T. Jackson, MD

Editor-in-chief

I. Jackson $(\bowtie)$

William Beaumont Hospitals,

Royal Oak, MI, USA

e-mail: eurjplastsurg@juno.com 